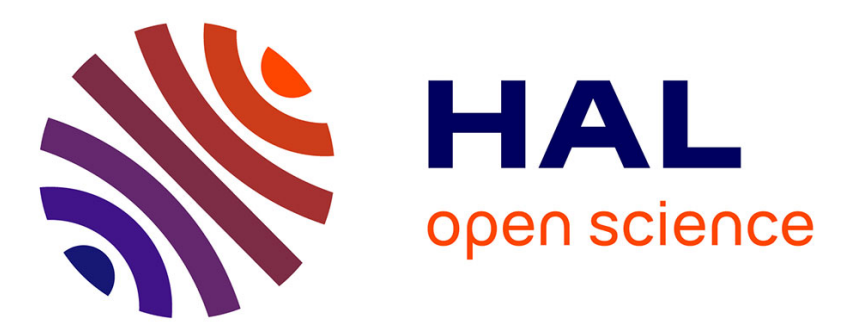

\title{
Mechanisms of Manganese Oxide Electrocatalysts Degradation during Oxygen Reduction and Oxygen Evolution Reactions
}

Florian Speck, Pietro Santori, Frederic Jaouen, Serhiy Cherevko

\section{To cite this version:}

Florian Speck, Pietro Santori, Frederic Jaouen, Serhiy Cherevko. Mechanisms of Manganese Oxide Electrocatalysts Degradation during Oxygen Reduction and Oxygen Evolution Reactions. Journal of Physical Chemistry C, 2019, 123 (41), pp.25267-25277. 10.1021/acs.jpcc.9b07751 . hal-02352336

\section{HAL Id: hal-02352336 https://hal.science/hal-02352336}

Submitted on 16 Nov 2020

HAL is a multi-disciplinary open access archive for the deposit and dissemination of scientific research documents, whether they are published or not. The documents may come from teaching and research institutions in France or abroad, or from public or private research centers.
L'archive ouverte pluridisciplinaire HAL, est destinée au dépôt et à la diffusion de documents scientifiques de niveau recherche, publiés ou non, émanant des établissements d'enseignement et de recherche français ou étrangers, des laboratoires publics ou privés. 


\title{
Mechanisms of Manganese Oxide Electrocatalysts Degradation
}

\section{during Oxygen Reduction and Oxygen Evolution Reactions}

Florian D. Speck ${ }^{1,2, *}$, Pietro G. Santori ${ }^{3}$, Frédéric Jaouen ${ }^{3, *}$, Serhiy Cherevko ${ }^{1, *}$

1 Helmholtz-Institute Erlangen-Nürnberg for Renewable Energy (IEK-11), Forschungszentrum Jülich, Egerlandstr. 3, 91058 Erlangen, Germany

2 Department of Chemical and Biological Engineering, Friedrich-Alexander-Universität Erlangen-Nürnberg, Egerlandstr. 3, 91058 Erlangen, Germany

3 Institut Charles Gerhardt Montpellier, UMR 5253, CNRS, Université Montpellier, ENSCM, Place Eugène Bataillon, 34095 Montpellier cedex 5, France

E-mail: F.D.S.f.speck@fz-juelich.de

E-mail: F.J. frederic.jaouen@umontpellier.fr

E-mail: S.C. s.cherevko@fz-juelich.de

\begin{abstract}
Anion exchange membrane fuel cells and electrolyzers offer a unique opportunity of using nonnoble metal electrocatalysts for catalyzing the sluggish oxygen reduction and oxygen evolution reactions (ORR, OER). In recent years, various $\mathrm{Mn}$-based oxides were identified as promising catalysts for both reactions. While electrocatalytic activity of such oxides is well addressed, their stability is still to be proven. Herein, we investigate the stability of four main manganese oxide allotropes by following their $\mathrm{Mn}$ dissolution rate in operando ORR and OER conditions. Using an electrochemical on-line inductively coupled plasma mass spectrometer (on-line ICP-MS), we uncover unexpected instability of this class of catalysts, with different degradation mechanisms identified under OER and ORR conditions. The reason for their degradation is shown to be related to the production of hydrogen peroxide species on manganese oxides during ORR. Furthermore, we discuss how limits in thermodynamically stable windows of each $\mathrm{Mn}$ oxidation state leads to increased dissolution during applications with high potential perturbations, i.e. change in load, start/stop conditions and especially bifunctional application. Therefore we recommend clear guidelines for future development of platinum group metal free electrocatalysts for affordable alkaline energy conversion technologies.
\end{abstract}




\section{Introduction}

Electrochemical energy conversion devices such as water electrolyzers (EL) and hydrogen fuel cells (FC) hold the promise for a closed electrocatalytic water cycle with high round-trip efficiency, allowing the storage of renewable energy and electricity generation, respectively. The state of the art in R\&D and commercialization are proton exchange membrane fuel cells (PEM-FC) and electrolyzers (PEM-EL). ${ }^{1-6}$ In both of these technologies, the electrochemical reactions at the positive electrode have been identified as the most challenging ones for electrocatalysis. ${ }^{7-10}$ In PEM-FCs, the oxygen reduction reaction (ORR) is the main limiting factor, both in overcoming ORR kinetic restrictions of the four electron process, as well as upscaling the technology due to the high price of $\mathrm{Pt}^{7,11-12}$ To overcome the latter, anion exchange membrane fuel cells (AEM-FCs) have been investigated with increasing attention in the last years, as they offer a more favorable environment for platinum group metal (PGM) free catalysts, both in terms of thermodynamic stability and ORR activity. ${ }^{13-14}$ Several recent research papers have also reported promising replacement of PGM- by PGM-free cathodes reaching peak powers $>1 \mathrm{~W} \mathrm{~cm}^{-2} \cdot{ }^{15-16}$ Furthermore, continuous progress in membrane development has drastically increased the initial power performance of AEM-FC, now at par or even higher than that reached with PEM-FCs, at a comparable total PGM loading in the entire membrane-electrode-assemblies. ${ }^{17-18}$ This advantage could lead to a significant reduction in the cost of FC technology if PGM loading at the anode of AEM-FC can be significantly reduced or zeroed in the future. For electrolyzers, state of the art PEM-EL faces the same challenges as encountered at the positive electrode of PEM-FC, namely high overpotential to drive the OER, even on the best PGM-based catalysts, and significant cost associated with the use of Ir oxide $\left(\mid \mathrm{rO}_{\mathrm{x}}\right)$ and $\mathrm{IrRuO}_{\mathrm{x}}$ catalysts as well as titanium bipolar plates. Here the price of the desired $\mathrm{H}_{2}$ production is mainly governed by the scarcity of relatively stable and active $\mathrm{IrO}_{\mathrm{x}}$ catalysts, needed to drive the anodic side reaction. ${ }^{19-20}$ Similar to the FC, switching to alkaline or high $\mathrm{pH}$ environment opens a broader selection of catalysts for the oxygen evolution reaction (OER), including numerous PGM-free and Earth-abundant metal oxides. While alkaline electrolyzers are already commercialized and compete for the market of low-temperature electrolyzers with PEM-EL, they suffer from higher internal cell resistance, less pure $\mathrm{H}_{2}$ produced and difficulty to electrochemically pressurize the hydrogen. For those reasons, AEM-EL are perceived as a promising technology that could unify the technical advantages of PEM-EL with the cost advantages of AEM-EL.

While the catalyst cost seems to not be an issue for AEM technology, the aforementioned sluggishness of the $4-\mathrm{e}^{-}$ORR and OER processes still needs urgent optimization to compete with PEM technology. To achieve this, research efforts are focused on a better understanding of electrocatalysis during ORR and OER on PGM-free catalysts in alkaline media. 
Numerous PGM-free catalysts have been investigated for catalyzing the ORR or OER in alkaline electrolytes. Ranging from metal oxides to perovskites for OER and ORR, ${ }^{21-23}$ all the way to advanced single atom $\mathrm{M}-\mathrm{N}-\mathrm{C}$ catalysts for ORR. ${ }^{21}$ Manganese is considered as an interesting candidate since in aqueous media at $\mathrm{pH} \mathrm{13,} \mathrm{thermodynamically} \mathrm{stable} \mathrm{oxidation} \mathrm{states} \mathrm{of} \mathrm{the}$ solid phase in equilibrium include $0,+\mathrm{II},+\mathrm{II} /+\mathrm{III},+\mathrm{II},+\mathrm{IV}$. In solution, stable ions reaching oxidation states of $+\mathrm{VI}$ and $+\mathrm{VII}$ are present. ${ }^{13,24}$ These thermodynamic considerations, however, neglect adsorbates and intermediates during electrocatalysis, as well as transient changes of the surface during potential cycling. Nevertheless, due to its abundance and associated low cost, rich redox chemistry and inspired by the key role of this element in Nature's photocatalytic water splitting systems, Mn-based materials have attracted a special attention. $^{20,25-28}$ Such materials have also been considered for bifunctional application, i.e. as a single device capable of both FC and EL operation, and for rechargeable metal-air batteries. ${ }^{28-30}$

Surprisingly, while Mn-oxides have been investigated in numerous studies for their activity in alkaline electrolyte toward ORR, OER, bifunctional ORR/OER, ${ }^{31-32}$ as well as toward hydrogen peroxide reduction or decomposition (e.g as tandem ORR catalysts with N-C or Fe-N-C catalysts) ${ }^{33-34}$, their stability has been hitherto relatively poorly investigated. While there are few reports, investigations on dissolution stability of $\mathrm{Mn}$ are rare, with bulk dissolution typically measured ex situ. ${ }^{35}$ For OER in acidic environment, a stable potential window for $\mathrm{MnO}_{\mathrm{x}}$ was recently derived from UV-vis spectroscopy measurements, ${ }^{36}$ with faradaic efficiencies for OER measured to be near unity in that potential window, pointing towards minimal corrosion current. ${ }^{23}$ In contrast, intense $\mathrm{Mn}$ dissolution starting at ca. $1.20 \mathrm{~V}_{\mathrm{RHE}}$ was observed for OER in alkaline electrolyte, and the onset of dissolution was related to the thermodynamic potential of $\mathrm{MnO}_{4}{ }^{-}$(aq) formation from $\mathrm{MnO}_{2}{ }^{37}$ Adverse studies reported the stabilization of $\mathrm{Mn}$ in perovskite materials by optimizing lattice parameters and excluded the possibility of $\mathrm{Mn}$ dissolution in alkaline electrolyte during OER in rotating ring disk electrode (RRDE) experiments. $^{20,38}$ However, most stability investigations usually rely on long term activity assessments and ex-situ physical methods. As J. Kibsgaard and I. Chorkendorff recently commented, apparent stable OER activity of metal-oxides is not a proof of material stability, since the continuous leaching of metal cations from an oxide surface may lead to a constantly changing oxide surface or even increased surface area, the leached metal ions exposing a new surface. ${ }^{6}$ Therefore, before moving towards application of $\mathrm{Mn}$ electrocatalysts in FC and EL, we find it crucial to gain improved understanding about the thermodynamic implications of $\mathrm{Mn}$ redox reactions in operando, as well as the effect of the catalysis reaction itself, which happens outside of thermodynamic equilibrium and can involve intermediate species such as $\mathrm{HO}_{2}{ }^{-}$not accounted for in classical thermodynamic considerations.

Herein, to uncover possible degradation mechanisms of Mn oxides in AEM-FC, AEM-EL and bifunctional FC/EL applications, we synthesized four manganese oxide allotropes 
commonly used in the literature, viz. $\alpha-\mathrm{Mn}_{2} \mathrm{O}_{3}, \alpha-\mathrm{MnO}_{2}, \beta-\mathrm{MnO}_{2}$, and $\delta-\mathrm{MnO}_{2}$, deposited them on carbon support, and investigated their dissolution rates during accelerated stress tests (ASTs) designed either for FC or EL operation modes in an alkaline medium. We also specifically investigated the effect of $\mathrm{O}_{2}$ or hydrogen peroxide present in the electrolyte on $\mathrm{Mn}$ dissolution rates and compared it to the dissolution rates acquired in an inert-gas saturated electrolyte. During ORR, we reveal that the in operando formation of $\mathrm{HO}_{2}{ }^{-}$on $\mathrm{MnO}_{\mathrm{x}}$ is the main driver of $\mathrm{Mn}$ dissolution, while during OER, the main driver is the $\mathrm{MnO}_{2} / \mathrm{MnO}_{4}^{-}$(aq) thermodynamic redox potential stability limitation. Lastly, apparent differences in the dissolution behavior between the four allotropes were ruled out by normalizing to the catalysts' specific surface areas. We conclude that none of the $\mathrm{MnO}_{\mathrm{x}}$ allotropes is satisfactorily stable, neither in ORR nor in OER operation modes in alkaline media and that strict guidelines to verify material stability should be especially followed for PGM free materials.

\section{Methods}

\subsection{Catalyst Synthesis and Preparation}

The preparation of four different, phase-pure, manganese oxides was targeted, namely the $\alpha-$, $\beta-, \delta-\mathrm{MnO}_{2}$ and $\alpha-\mathrm{Mn}_{2} \mathrm{O}_{3}$ phases. Their synthesis was performed according to the literature. In short, $\alpha-\mathrm{MnO}_{2}$ was obtained by reducing $\mathrm{KMnO}_{4}(3.16 \mathrm{~g})$ in a mixture of water $(200 \mathrm{~mL})$ and fumaric acid $(0.78 \mathrm{~g})$, kept under stirring at room temperature for 30 minutes. The resultant gel is settled for $1 \mathrm{~h}$ and then filtered, washed with ultrapure water and dried to yield $\alpha-\mathrm{MnO}_{2}{ }^{39}$ The reduction of $\mathrm{KMnO}_{4}(0.395 \mathrm{~g})$ to $\delta-\mathrm{MnO}_{2}$ was carried out under stirring over $3 \mathrm{~h}$ in a mixture of water $(80 \mathrm{~mL}), \mathrm{H}_{2} \mathrm{SO}_{4}(96 \%, 70.2 \mu \mathrm{L})$ and ethanol $(3 \mathrm{~mL}){ }^{40}$ The dried powder was calcined at $450{ }^{\circ} \mathrm{C}$ to yield $\beta-\mathrm{MnO}_{2}{ }^{41} \alpha-\mathrm{Mn}_{2} \mathrm{O}_{3}$ was obtained by calcining $\mathrm{\gamma}-\mathrm{MnOOH}$ at $550{ }^{\circ} \mathrm{C}^{14}$ The latter was obtained via $\mathrm{KMnO}_{4}(0.2 \mathrm{~g})$ reduction together with $\mathrm{Mn}\left(\mathrm{CH}_{3} \mathrm{COO}\right)_{2} \cdot 4 \mathrm{H}_{2} \mathrm{O}$ $(1.2 \mathrm{~g})$ in water $(150 \mathrm{~mL})$ over $12 \mathrm{~h}$, keeping the mixture under stirring and refluxed. ${ }^{42}$ Subsequently, the four manganese oxides were dispersed on carbon black (CABOT, Vulcan ${ }^{\circledR}$ $\mathrm{XC72R}$ ), with a ratio of $1: 5$, placed in zirconia jars with 100 balls ( $0.4 \mathrm{~g}$ per ball) and mixed at low energy ball milling (Fritsch, Pulverisette 7) for 10 minutes at 200 rpm.

For scanning flow cell (SFC) measurements, the catalyst materials were dropcast onto a glassy cacrrbon (GC) plate (HTW, Sigradur $\left.{ }^{\circledR}\right)$. Therefore $5 \mathrm{mg}$ of catalyst were dispersed firstly in water (Merck, Milli-IQ ${ }^{\circledR}$ IQ 7000, $18.2 \mathrm{M} \Omega, 1176 \mu \mathrm{l}$ ) using a sonication horn (Branson, SFX 150) for 10 minutes at 4 second intervals of $40 \%$ amplitude while cooling in an ice bath. Afterwards, Nafion ${ }^{\circledR}$ perfluorinated resin solution (Sigma Aldrich, 5 wt.\%, $28.6 \mu \mathrm{L}$ ) with isopropanol $(294 \mu \mathrm{L}$ Merck, Emsure ${ }^{\circledR}$ ) was added and sonicated again. This concentrated ink was further diluted by half using equal parts of the ink and water and subsequently the $\mathrm{pH}$ was adjusted to 11 using $\mathrm{NaOH}$ (Merck, Suprapur ${ }^{\circledR}, 0.05 \mathrm{M}$ ). After a final sonication step, catalyst spots were dropcast onto a GC plate from $0.2 \mu \mathrm{L}$ of the ink ( $\left.c=3.34 \mathrm{~g} \mathrm{~L}^{-1}, \mathrm{~m}_{\text {cat }} / \mathrm{m}_{\text {ion }}=4\right)$ yielded spots with a radius of $0.65 \mathrm{~mm} \pm 0.03 \mathrm{~mm}\left(\approx 50 \mu \mathrm{g} \mathrm{cm}^{-2}\right)$, which was measured for each spot using a laser scanning 
microscope (Keyence, VK-X250) and used for normalization of all electrochemical and dissolution data towards geometric surface area.

\subsection{On-line ICP-MS}

For all stability investigations we used an inductively coupled plasma mass spectrometer (ICP-MS) (Perkin Elmer, NexION 350x) for the in situ detection of dissolved manganese species, by coupling it to the electrolyte outlet of a custom made polycarbonate SFC. On the electrolyte inlet (angled $60^{\circ}$ to the outlet) the SFC was connected to a graphite counter electrode (Sigma Aldrich, 99.995\% trace metal basis). A third capillary channel connected the reference electrode (Metrohm, $\mathrm{Ag} / \mathrm{AgCl}$ ) closely to the working electrode surface. Contact with the working electrode was made with a translation stage (Physik Instrumente, M-403). A Potentiostat (Gamry, Reference 600) was used to employ all electrochemical protocols during dissolution measurements. The purged electrolytes flow rate was controlled and regularly calibrated by the peristaltic pump of the ICP-MS (Elemental Scientific, MP2 Pump). The sensitivity of the ICP-MS towards dissolved Mn ions was calibrated daily from Mn calibration standards (Merck, Centripur ${ }^{\circledR}$ ) and dissolution rates are normalized to the geometric surface area of each catalyst spot. For further information on the experimental SFC ICP-MS setup, please refer to our previous reports. ${ }^{43}$

As an electrolyte $\mathrm{NaOH}$ (Merck, Suprapur) was dissolved in water to $0.05 \mathrm{M}$. For individual experiments, an addition of small amounts of $30 \mathrm{wt} . \% \mathrm{H}_{2} \mathrm{O}_{2}$ (Merck) was achieved by multiple dilution steps. The $\mathrm{pH}$ was controlled (Mettler Toledo, SevenExcellence) and used to convert the potentials of the $\mathrm{Ag} / \mathrm{AgCl}$ to the reversible hydrogen electrode (RHE) using equation (Eq. 1).

\subsection{RRDE Experiments}

$$
E_{\mathrm{RHE}}=\mathrm{E}_{\mathrm{applied}}+\mathrm{E}_{\mathrm{Ag} / \mathrm{AgCl}}+0.0591 \times \mathrm{pH}
$$

Rotating ring disk electrode (RRDE) analysis was performed in $0.05 \mathrm{M} \mathrm{NaOH}$ employing a conventional three-electrode setup, where all electrodes were connected to a Potentiostat (BioLogic, SP-300). Using a RHE, based on a Pt-wire immersed in $\mathrm{H}_{2}$-satured electrolyte inside a fritted glass, as the reference electrode and a graphite rod as the counter electrode.

The ink is prepared by mixing $5 \mathrm{mg}$ of the catalyst with $54 \mu \mathrm{L}$ of Nafion ${ }^{\circledR}, 744 \mu \mathrm{L}$ ethanol and $92 \mu \mathrm{L}$ ultrapure water and subsequent sonication for $1 \mathrm{~h}$ in an ice bath. Drop casting of $8.8 \mu \mathrm{L}$ dispersion onto the glassy carbon RRDE yielded a catalyst loading of $0.25 \mathrm{mg} \mathrm{cm}^{-2}$, after drying the droplet at room temperature. The active surface area is determined applying cyclic voltammograms (CVs) in $\mathrm{N}_{2}$-saturated electrolyte in a range potential of $1-0.45 \mathrm{~V}$ (Figure S5), with a scan rate of $5 \mathrm{mV} \mathrm{s}^{-1}$ and a rotation rate of $1600 \mathrm{rpm}$ (identical for all the experiments). Afterwards, activity is evaluated in $\mathrm{O}_{2}$-saturated electrolyte in a potential range of $1-0 \mathrm{~V}$, at a 
scan rate of $5 \mathrm{mV} \mathrm{s}^{-1}$. Lastly, by applying $1.2 \mathrm{~V}_{\mathrm{RHE}}$ to the Pt ring, the amount of $\mathrm{HO}_{2}^{-}$produced during the oxygen reduction reaction (ORR) could be obtained.

\subsection{Physical Analysis}

X-ray Photoelectron Spectroscopy (XPS) was conducted using a PHI Quantera II scanning X-ray microprobe. Spectra of catalyst spots $\left(90 \mu \mathrm{g} \mathrm{cm}^{-2}\right)$ on $\mathrm{GC}$ were acquired using Al-K $\alpha$ irradiation of a $200 \mu \mathrm{m}$ diameter spot at $50 \mathrm{~W}$ and $15 \mathrm{kV}$. Survey scans at a step size of $1 \mathrm{eV}$ and $280 \mathrm{eV}$ pass energy as well as high resolution narrow scans in $0.125 \mathrm{eV}$ steps at $140 \mathrm{eV}$ pass energy were collected for 500 ms dwell time per step. Data was analyzed in CasaXPS (V.2.3.18) using instrument specific relative sensitivity factors, Shirley type backgrounds and a binding energy scale calibrated to the adventitious carbon peak at $284.8 \mathrm{eV}$.

$X$-ray Diffraction (XRD) patterns were measured on a PANAlytical X'pert diffractometer in Bragg-Brentano configuration, using $\mathrm{CuK}_{\alpha}$ source $(\lambda=1.5406 \AA)$ in a $2 \theta$ range of $5-80^{\circ}$ in a step size of $0.035^{\circ}$. The most intense reflexes are compared in PANalytical $X^{\prime}$ Pert Highscore Plus (version 3.0e) to literature data taken from $\alpha-\mathrm{MnO}_{2}{ }^{44} \beta-\mathrm{MnO}_{2}{ }^{45} \delta-\mathrm{MnO}_{2},{ }^{46} \mathrm{Mn}_{2} \mathrm{O}_{3}{ }^{47}$. The same literature data was also taken to simulate the ideal XRD patterns (FWHM $=0.1^{\circ} 2 \theta$ ) in Figure 2a, using Mercury 4.0.0. Crystallite sizes D were estimated using the transformed Scherrer Equation (Eq. 2) using a shape factor $K=0.9$.

$$
D=\frac{K \lambda}{\Delta 2 \Theta_{F W H M} \cos \Theta}
$$

Here, $\Delta 2 \Theta_{\mathrm{FWHM}}$ is the main reflex' width at 0.5 normalized intensity in radiants and $\theta$ its position.

A Hitachi S4800 SEM was used to acquire images of the materials morphology.

The catalysts porosity was determined from $\mathrm{N}_{2}$ sorption isotherms at $77 \mathrm{~K}$ using the BET Method. Isotherms were recorded on all catalysts using a Micromeritics ASAP 2020 instrument. 


\section{Results}

\subsection{Catalyst characterization}

The synthesized $\mathrm{MnO}_{\mathrm{x}}$ materials were investigated using X-ray diffraction (XRD) and X-ray photoelectron spectroscopy (XPS) to confirm their crystal structure and oxidation state. Figure 1 shows a summary of the physical catalyst analysis.
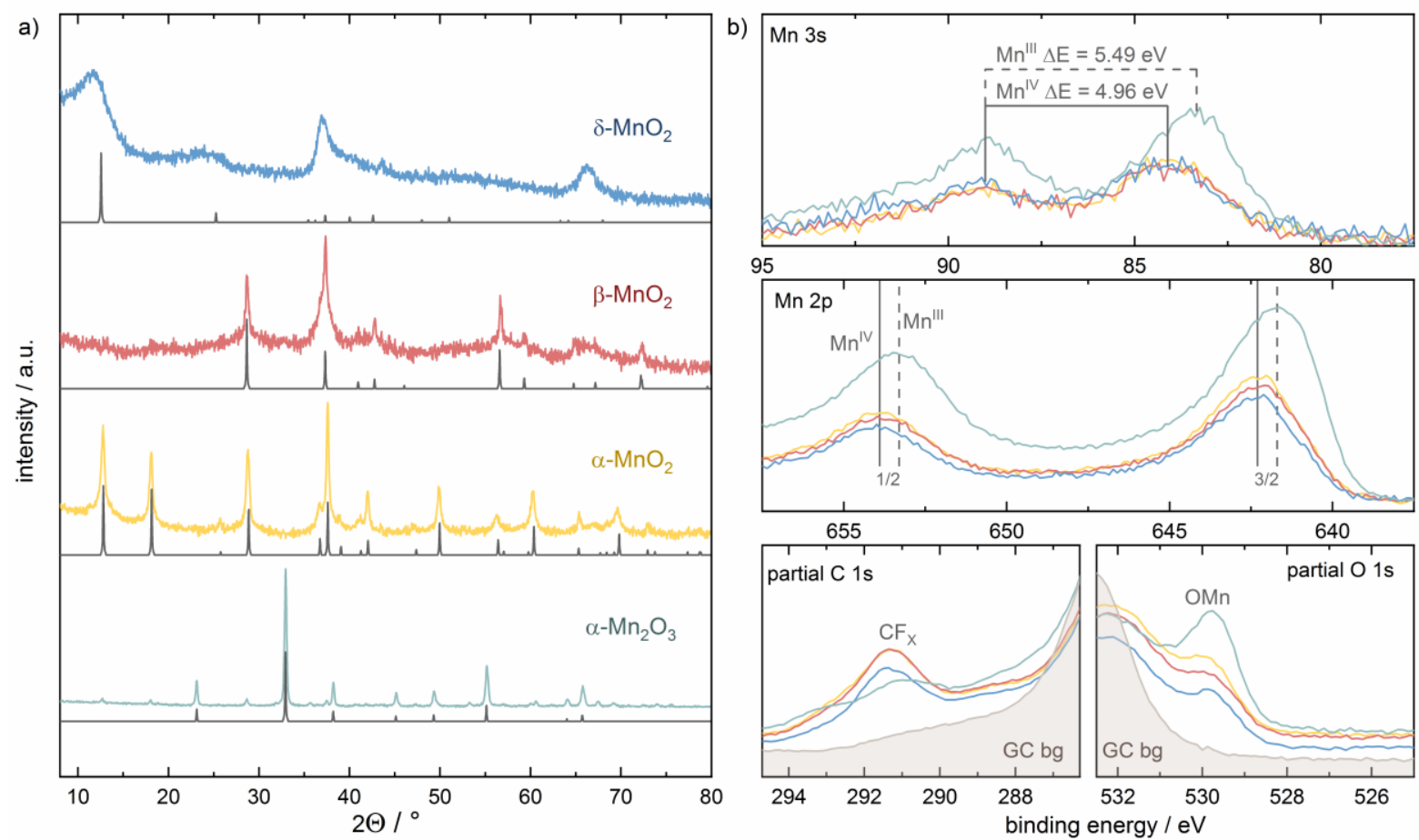

Figure 1. Structural and compositional analysis of the $\mathrm{MnO}_{\mathrm{x}}$ materials. (a) XRD patterns of the as synthesized $\alpha-\mathrm{Mn}_{2} \mathrm{O}_{3}, \alpha-\mathrm{MnO}_{2}, \beta-\mathrm{MnO}_{2}$ and $\delta-\mathrm{MnO}_{2}$ materials compared to calculated positions of the reflexes for the targeted allotropes, using Mercury (4.0.0). (the assigned reflexes can be found in Figure S1) (b) XPS analysis of the dropcasted inks, containing Vulcan ${ }^{\circledR}$ Carbon and Nafion ${ }^{\circledR}$ is shown in form of the $\mathrm{Mn} \mathrm{3s,} \mathrm{Mn} 2 \mathrm{p}$ regions as well as partial $\mathrm{C} 1 \mathrm{~s}$ and $\mathrm{O} 1 \mathrm{~s}$ regions, selected to highlight $\mathrm{C}-\mathrm{F}$ and $\mathrm{O}-\mathrm{Mn}$ interactions, respectively.

For the studied $\mathrm{MnO}_{\mathrm{x}}$ materials, the position of the main XRD reflexes in the recorded patterns (Figure 1a) is in line with literature data, ${ }^{44-45,48-49}$ confirming successful synthesis of the targeted phases. As can be seen in Fig. 1a, some minor reflexes in the XRD pattern of the sample labelled as $\alpha-\mathrm{Mn}_{2} \mathrm{O}_{3}$ can be assigned to $\alpha-\mathrm{MnO}_{2}$. Using MAUD software, we quantified that $5 \% \alpha-\mathrm{MnO}_{2}$ co-exists within the sample labelled as $\alpha-\mathrm{Mn}_{2} \mathrm{O}_{3}$. Further, the crystallinity, estimated from the broadness at full width half maximum (FWHM) of the most intense diffraction reflexes, decreases in the order $\alpha-\mathrm{Mn}_{2} \mathrm{O}_{3}>\alpha-\mathrm{MnO}_{2}>\beta-\mathrm{MnO}_{2}>\delta-\mathrm{MnO}_{2}$. Using the Scherrer equation we estimate crystal sizes (D) of $34.9>31.3>20.1>>1.4 \mathrm{~nm}$. 
XPS survey scans of the $\mathrm{MnO}_{\mathrm{x}} / \mathrm{C}$ catalyst ink deposited on glassy carbon (GC), presented in Figure S2, show the presence of $\mathrm{C}, \mathrm{F}, \mathrm{O}, \mathrm{Mn}$ and $\mathrm{S}$ at the catalyst surface while only $\mathrm{C}$ and $\mathrm{O}$ are detected at the GC reference surface. The $\mathrm{F}$ and $\mathrm{S}$ signals seen on the catalyst surface originate from the $\mathrm{Nafion}^{\circledR}$ ionomer in the dried ink while the $\mathrm{C}$ signal originates from the Vulcan $^{\circledR}$ (XC72R) support as well as from the underlying GC plate. Therefore, Figure $1 \mathrm{~b}$ focuses on narrow, high resolution scans of the $\mathrm{Mn} 2 \mathrm{p}, \mathrm{Mn3s}$ as well as partial $\mathrm{C} 1 \mathrm{~s}$ and $01 \mathrm{~s}$ regions to identify the surface composition and oxidation state of $\mathrm{MnO}_{x}$. Both $\mathrm{Mn}$ regions of the $\mathrm{Mn}_{2} \mathrm{O}_{3}$ sample clearly show a higher $\mathrm{Mn}$ atomic concentration. Further, a more defined peak in the $\mathrm{O} 1 \mathrm{~s}$ signal at $529.8 \mathrm{eV}$ compared to the other three $\mathrm{MnO}_{2}$ materials, is assigned to $\mathrm{O}-\mathrm{Mn}$ interaction as a feature next to the adventitious 01 s peak that is also observed on the pure GC background spectra (GC bg) $)^{50}$. Most indicative of the lower average surface oxidation state of $\mathrm{Mn}$ for the $\mathrm{Mn}_{2} \mathrm{O}_{3}$ sample is the increased multiplet splitting (5.49 eV) of the Mn3s scan and the shift of the $M n 2 p_{1 / 2}$ and $M n 2 p_{3 / 2}$ peaks to lower binding energies (641.7 eV and $653.3 \mathrm{eV}$, respectively) compared to the $\mathrm{Mn}^{\mathrm{IV}} \mathrm{O}_{\mathrm{x}}$. Supporting the XRD findings (co-existence of $5 \% \alpha-\mathrm{MnO}_{2}$ with $95 \% \mathrm{Mn}_{2} \mathrm{O}_{3}$ in the material labelled $\mathrm{Mn}_{2} \mathrm{O}_{3}$ ), we find $25 \% \mathrm{Mn}^{\mathrm{IV}}$ and $75 \% \mathrm{Mn}^{\mathrm{III}}$ on the catalyst surface, using CasaXPS peak fitting capabilities employing instrument specific relative sensitivity factors. This increased $\mathrm{Mn}^{\mathrm{IV}}$ content as compared to XRD is to be expected if the higher oxidation state occurs mainly at the surface due to post synthesis effects, since XRD only gives us the bulk composition. In contrast, the three $\mathrm{Mn}^{\mathrm{IV}}$-oxide materials show superimposed Mn3s and $2 p$ regions, with a $3 s$ multiplet splitting of $4.96 \mathrm{eV}$ and $\mathrm{Mn} 2 \mathrm{p}_{3 / 2}$ peak at $642.3 \mathrm{eV}^{24}$ The $01 \mathrm{~s}$ peak of each $\mathrm{Mn}^{\mathrm{IV}}$-oxide at $529.8 \mathrm{eV}$ appears only as a shoulder to the adventitious $01 \mathrm{~s}$ peak. The C1s region displays a specific feature at $291.3 \mathrm{eV}$ in all catalyst spots, which corresponds to Nafion $^{\circledR}$ (i.e. $\left.\mathrm{F}-\mathrm{C}\right)^{51}$ carbon which is not present on the pure GC scan.

The morphology of the catalysts was investigated using scanning electron microscope (SEM) analysis, shown in Figure S3. The various synthesis routes selected to prepare the phase-pure $\mathrm{MnO}_{\mathrm{x}}$ materials resulted in different morphologies. All materials seem to consist of sintered particles, however, the surface roughness increases from compact material $\left(\alpha-\mathrm{Mn}_{2} \mathrm{O}_{3}\right)$ to more platelet looking sheets $\left(\delta-\mathrm{MnO}_{2}\right)$ which correlates with the crystal size estimated by XRD. Using the Brunauer Emmett Teller (BET) equation applied to $\mathrm{N}_{2}$ sorption isotherms gathered of the unsupported $\mathrm{MnO}_{\mathrm{x}}$ materials, we confirm that the surface area is inversely correlated with the average crystal size estimated from the XRD patterns. $\left(\alpha-\mathrm{Mn}_{2} \mathrm{O}_{3} ; 14 \mathrm{~m}^{2} \mathrm{~g}^{-1}\right.$ $\left.>\alpha-\mathrm{MnO}_{2} ; 98 \mathrm{~m}^{2} \mathrm{~g}^{-1}>\beta-\mathrm{MnO}_{2} ; 136 \mathrm{~m}^{2} \mathrm{~g}^{-1}>\delta-\mathrm{MnO}_{2} ; 214 \mathrm{~m}^{2} \mathrm{~g}^{-1}\right)$, see Figure S4. Since the BET area is not necessarily a direct descriptor of the electrochemical surface area (ECSA), cyclic voltammetry (CV) in $\mathrm{N}_{2}$-saturated electrolyte was performed on the $\mathrm{MnO}_{\mathrm{x}} / \mathrm{C}$ materials, with a RRDE setup, with data presented in Figures S5 and S6. Most notably, Figure S5 shows the initial changes occurring during the first six CVs performed after immersion in the electrolyte. Since the cathodic current is usually larger than the anodic one in the scanned potential range, we anticipate that the surface of all polymorphs slowly converts to the mixed $\mathrm{Mn}^{\text {IIIII }}$ valence state 
during potential cycling. Furthermore, the intensity of the redox couple centered at around $0.75 \mathrm{~V}_{\mathrm{RHE}}$ in the first CV follows the same trend as the BET area measured for unsupported $\mathrm{MnOx}$ materials, or as $\mathrm{D}^{-1}$. As directly compared in Figure S5, the charge passed could therefore reflect the trend of ECSA and therefore confirms good correlation with the BET area. Lastly Figure $\mathrm{S} 6$ provides linear sweep voltammograms (LSV) in $\mathrm{O}_{2}$ purged environment to compare ORR activity with the $\mathrm{HO}_{2}^{-}$yields of the various $\mathrm{MnO}_{x}$ catalysts. The LSVs in Figure S6b show

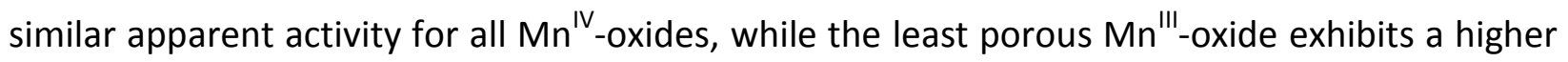
overpotential towards ORR. All $\mathrm{MnO}_{\mathrm{x}}$ catalysts supported on carbon, however, produce significant amounts of $\mathrm{HO}_{2}{ }^{-}$as detected by the ring current, starting at $0.71 \mathrm{~V}$ RHE, and reaching yields of up to $16 \%$ at lower potential.

\subsection{Degradation during the oxygen reduction reaction}

To understand the degradation of Mn oxide-based catalysts during FC operation, dissolution of $\mathrm{Mn}$ is studied first in the ORR potential region. As a representative example, the dissolution of $\mathrm{Mn}$ from the $\delta-\mathrm{MnO}_{2}$ catalyst is shown in Figure 2. The on-line dissolution rate of $\mathrm{Mn}, \mathrm{ORR}$ current density and $\mathrm{HO}_{2}{ }^{-}$production yield during negative-going LSV are presented in Figure $2 \mathrm{a}$, $2 \mathrm{~b}$ and $2 \mathrm{c}$, respectively, as a function of potential.

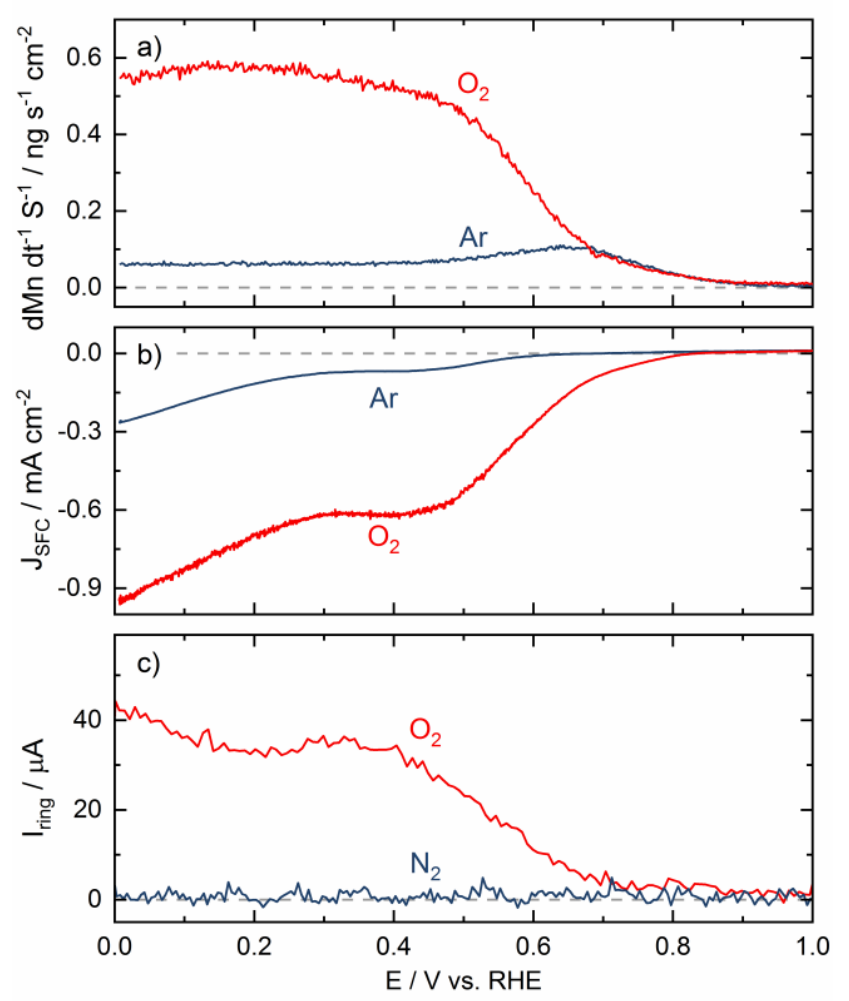

Figure 2. Dissolution rate (a) and current density (b) in the SFC as well as $\mathrm{HO}_{2}{ }^{-}$yields in a RRDE setup (c) measured for $\delta-\mathrm{MnO}_{2}$ in argon- (blue) and oxygen-purged (red) $0.05 \mathrm{M} \mathrm{NaOH}$ 
electrolyte. LSV was performed by scanning from 1 to $0 \mathrm{~V}_{\mathrm{RHE}}$, at a scan rate of $5 \mathrm{mV} \mathrm{s}{ }^{-1}$. The flow rate in the SFC was $3.65 \mu \mathrm{L} \mathrm{s}^{-1}$.

Starting at $1.0-0.9 \mathrm{~V}_{\mathrm{RHE}}$, neither dissolution (Figure 2a) nor any significant current (Figure $2 \mathrm{~b}$ ) are detected in SFC, both in $\mathrm{Ar}$ and $\mathrm{O}_{2}$ purged electrolytes. While the negligible ring currents suggest that no $\mathrm{HO}_{2}^{-}$is being produced at the disk (Figure 2c). At a slightly lower potential, the onset of $\mathrm{Mn}$ dissolution is detected at $0.88 \mathrm{~V}_{\mathrm{RHE}}$, independent of the nature of the purging gas. The onset of dissolution is defined as the potential at which the ICP-MS signal is three times higher than the standard deviation of the baseline signal. This dissolution onset potential value corresponds well to the theoretical (th) potential of $\mathrm{Mn}^{\mathrm{IV}}$ reduction to $\mathrm{Mn}^{\text {III }}\left(\mathrm{E}_{\mathrm{th}}=0.95 \mathrm{~V}\right) .^{13}$ We correlate the onset potential of $\mathrm{Mn}$ dissolution to thermodynamic limits of stability, since a change in surface oxidation state usually corresponds to rearrangement of the structure leading to increased dissolution. ${ }^{52-53}$

Interestingly, additional to dissolution triggered by $\mathrm{Mn}^{\mathrm{IV}}$ reduction, online ICP-MS data reveals an increasing $\mathrm{Mn}$ dissolution rate in $\mathrm{O}_{2}$ - vs Ar-purged environment at potentials at which the ORR proceeds at significant rate at $0.68 \mathrm{~V}_{\mathrm{RHE}}$. A more detailed inspection of the results in Figure 2 shows that the additional $\mathrm{Mn}$ dissolution at low potential is closely related to the $\mathrm{HO}^{-}$species detected at the ring than with the ORR current density itself. In particular, in the restricted potential range of 0.7-0.8 $\mathrm{V}_{\mathrm{RHE}}$, significant ORR current is measured but without production of peroxide and without higher $\mathrm{Mn}$ dissolution rate than what was measured in $\mathrm{Ar}$ saturated electrolyte (Figure 2a). As soon as peroxide is detected at the ring, however, the $\mathrm{Mn}$ dissolution rate becomes higher than what was measured in Ar-purged electrolyte (Figure 2a). In the range 0.7 to $0.0 \mathrm{~V}_{\mathrm{RHE}}$, a correlation between $\% \mathrm{HO}_{2}^{-}$and $\mathrm{Mn}$ dissolution rate in $\mathrm{O}_{2}$ is observed, suggesting that peroxide products play an active role in enhancing the $\mathrm{Mn}$ dissolution rate.

To confirm the detrimental effect of ORR $\left(\mathrm{HO}_{2}{ }^{-}\right.$produced during $\left.\mathrm{ORR}\right)$ on the stability of other $\mathrm{MnO}_{x}$ polymorphs, we applied $\mathrm{CVs}_{\text {in }} \mathrm{O}_{2}$-purged electrolyte with three different potential ranges that have been typically used in the FC literature as accelerated stress tests (ASTs), to the four MnOx allotropes previously described. ${ }^{54}$ These three different $\mathrm{CV}$ ranges are herein labelled as load, high load and start/stop cycles with corresponding potential ranges of $1.0-$ $0.6,1.0-0$ and $1.0-1.5 \mathrm{~V}_{\mathrm{RHE}}$, respectively. Figure 3a compares the $\mathrm{Mn}$ dissolution rates of all four catalysts in $\mathrm{O}_{2}$ (red) and $\mathrm{Ar}$ (blue) saturated electrolyte. The nature of the purging gas does not change the position of the $\mathrm{Mn}^{\mathrm{IV}}$ oxide dissolution at $0.88 \mathrm{~V}_{\mathrm{RHE}}$. This dissolution onset is assigned to $\mathrm{Mn}^{\mathrm{IV}}$ to $\mathrm{Mn}{ }^{\mathrm{III}}$ surface reduction and reconstruction, and is expected to be the same for all $\mathrm{MnO}_{2}$ oxides since oxides and metal ions in electrolyte follow the same thermodynamic standard potentials. For the $\mathrm{Mn}$ "II oxide $\left(\mathrm{Mn}_{2} \mathrm{O}_{3}\right)$, the onset of $\mathrm{Mn}$ dissolution is shifted to lower potential $\left(0.63 \mathrm{~V}_{\mathrm{RHE}}\right)$ and corresponds to the reduction to a mixed valence $\mathrm{Mn}{ }^{1 / / I I}$ oxide 
$\left(0.69 \mathrm{~V}_{\mathrm{th}}\right) .{ }^{13}$ As reported above for $\delta-\mathrm{MnO}_{2}$, the presence of oxygen in the electrolyte, has also a strong impact on the $\mathrm{Mn}$ dissolution rate (compare red and blue curves in Figure 3a).
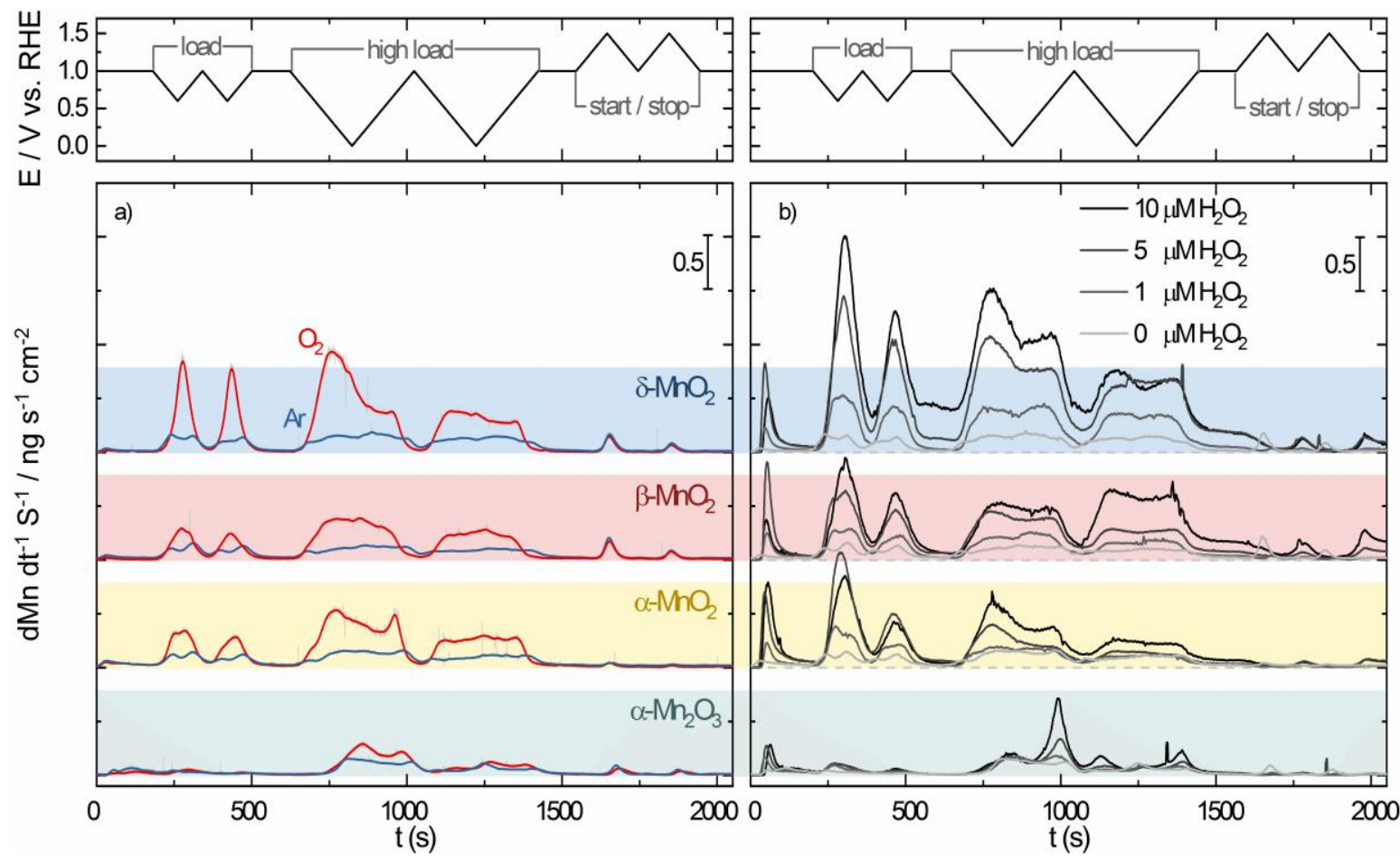

Figure 3. $\mathrm{Mn}$ dissolution rate from four $\mathrm{MnO}_{\mathrm{x}}$ within commonly used potential ranges at $5 \mathrm{mV} \mathrm{s}^{-1}$ (load cycles: $1-0.6 \mathrm{~V}_{\mathrm{RHE}}$, high load cycles: $1-0 \mathrm{~V}_{\mathrm{RHE}}$, start/stop cycles: $1-1.5 \mathrm{~V}_{\mathrm{RHE}}$ ). (a) Data gathered in both oxygen (red) and argon (blue) purged $0.05 \mathrm{M} \mathrm{NaOH}$. The data shown here is smoothed using a 20 point FFT Filter, while the raw data is shown as a pale grey line. (b) Catalyst dissolution in Ar purged $0.05 \mathrm{M} \mathrm{NaOH}$ for various $\mathrm{H}_{2} \mathrm{O}_{2}$ concentrations $(0,1,5,10 \mu \mathrm{M})$.

Similar to the results in Figure 2, one can clearly see that the ORR induces significantly increased $\mathrm{Mn}$ dissolution on all studied materials in the load cycles. On the other hand, during start/stop cycles (no ORR taking place, even in $\mathrm{O}_{2}$-purged electrolyte), the $\mathrm{Mn}$ dissolution rates are similar for a given $\mathrm{MnO}_{\mathrm{x}}$ structure in $\mathrm{Ar}$ - and $\mathrm{O}_{2}$-purged electrolyte. This independently confirms that ORR plays a role (direct or indirect) in enhanced Mn dissolution.

As extrapolated from the RRDE results in Figure 2 for $\delta-\mathrm{MnO}_{2}$, reactive oxygen species (ROS) formed during the ORR are expected to also trigger enhanced Mn dissolution of the other $\mathrm{MnO}_{\mathrm{x}}$ allotropes (Figure S6a). Therefore, experiments in Ar-purged electrolyte but with various amounts of intentionally added $\mathrm{H}_{2} \mathrm{O}_{2}$ were performed. Figure $3 \mathrm{~b}$ shows the impact of $\mathrm{HO}_{2}{ }^{-}$ concentration on Mn dissolution during the different LSV protocols. The figure reveals that $\mathrm{Mn}$ dissolution increases with increased $\mathrm{H}_{2} \mathrm{O}_{2}$ concentration in the electrolyte. In contrast to Figure $3 a$, where increased $\mathrm{Mn}$ dissolution is observed only at potentials at which the ORR occurs (i.e. potentials at which peroxide is formed in situ), in Figure $3 \mathrm{~b}$ increased Mn dissolution 
is observed at any potential when comparing peroxide-containing solution to peroxide-free solution. This unambiguously demonstrates that it is peroxide, and not ORR or presence of $\mathrm{O}_{2}$, which triggers the enhanced $\mathrm{Mn}$ dissolution.

To obtain quantitative information on the absolute amount of dissolved $\mathrm{Mn}$, the dissolution profiles were integrated over the time scale. Figure 4a shows the total dissolved amount (TDA) of $\mathrm{Mn}$ during the first two load cycles, for all studied materials. In Ar-purged electrolyte, the TDA trend is as follows, $\delta-\mathrm{MnO}_{2} \approx \beta-\mathrm{MnO}_{2} \approx \alpha-\mathrm{MnO}_{2} \gg \alpha-\mathrm{Mn}_{2} \mathrm{O}_{3}$. In $\mathrm{O}_{2}$-purged electrolyte, the TDA trend is $\delta-\mathrm{MnO}_{2}>\beta-\mathrm{MnO}_{2} \approx \alpha-\mathrm{MnO}_{2}>\alpha-\mathrm{Mn}_{2} \mathrm{O}_{3}$. To quantify the impact of purge gas, the TDA in oxygen was divided by the TDA in argon with results presented on the right $y$-axis in Figure 4a. Here, $\alpha-\mathrm{Mn}_{2} \mathrm{O}_{3}, \alpha-\mathrm{MnO}_{2}$ and $\beta-\mathrm{MnO}_{2}$ dissolve twice as much in oxygen, while still following the same stability trend. As for $\delta-\mathrm{MnO}_{2}$, it dissolves three times as much in $\mathrm{O}_{2}$-purged electrolyte. The total loss of $\mathrm{Mn}$ during load and high load cycles in varying $\mathrm{H}_{2} \mathrm{O}_{2}$ concentrations is shown in Figure $4 \mathrm{~b}$, revealing the same stability trends as observed in Figure $4 a$ between crystal structure and TDA, where $\delta-\mathrm{MnO}_{2}$ is the least stable structure, followed by $\beta-\mathrm{MnO}_{2} \approx \alpha-\mathrm{MnO}_{2}$ and $\alpha-\mathrm{Mn}_{2} \mathrm{O}_{3}$ is apparently more stable, in the presence of $\mathrm{H}_{2} \mathrm{O}_{2}$. Also, the increase of TDA with increasing peroxide concentration is quite restricted for $\alpha-\mathrm{Mn}_{2} \mathrm{O}_{3}$ vs. the others (compare TDA at 0 and $10 \mu \mathrm{M}$ for each $\mathrm{MnO}_{\mathrm{x}}$ ).
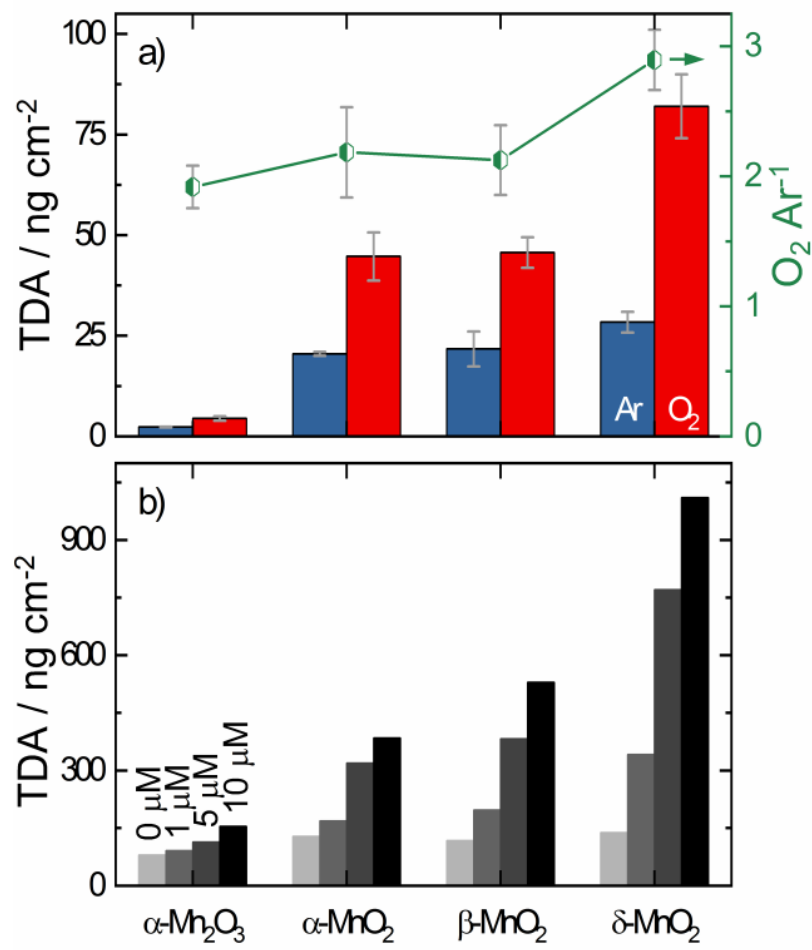

Figure 4. (a) The integral of $M n$ online dissolution (left $y$-axis, $M n_{\text {diss }}$ ) during two load cycles in $\operatorname{Ar}$ (blue) and $\mathrm{O}_{2}$ (red) saturated electrolyte. The factor of dissolution increase during ORR is 
shown on the right $\mathrm{y}$-axis (green). (b) Dependence of $\mathrm{Mn}$ dissolution on $\mathrm{H}_{2} \mathrm{O}_{2}$ concentration during load and high load cycle experiments in argon purged $0.05 \mathrm{M} \mathrm{NaOH}$.

In previous dissolution studies we recognized that there are typically two main dissolution processes, namely transient and steady state dissolution, characterized by short lived dissolution during potentiodynamic scans and constant dissolution during potentials holds, respectively. ${ }^{19,55-56}$ Therefore, we explored the effect of oxygen on Mn stability further by performing chronoamperometric (CA) ORR experiments at $0.6 \mathrm{~V}_{\mathrm{RHE}}$ in oxygenated electrolyte to measure the steady state dissolution. Figures 5 a shows current vs. time profiles of ORR on the $\mathrm{MnO}_{\mathrm{x}}$ and Figure $5 \mathrm{~b}$ the corresponding steady state $\mathrm{Mn}$ dissolution rate vs. time curves. At $0.6 \mathrm{~V}_{\mathrm{RHE}}, \mathrm{Mn}^{\mathrm{IV}}$ is reduced to $\mathrm{Mn}{ }^{\mathrm{III}}$, as follows from Figure $\mathrm{S} 5$ and additionally confirmed by XPS spectra presented in Figure $5 \mathrm{c}$. When we compare the photoelectron spectra of the Mn3s region before ORR (Figure 1 b) with the ones presented here after the experiment (Figure 5c), it becomes clear that the surface of all catalysts fully assimilated the thermodynamically favorable oxidation state at the imposed potential of $0.6 \mathrm{~V}_{\mathrm{RHE}}$, which is the $\mathrm{Mn}{ }^{\mathrm{III}}$ oxide. This is most obvious in the $\mathrm{Mn} 3 \mathrm{~s}$ region, where the multiplet splitting parameters of all $\mathrm{Mn}^{\mathrm{IV}}$-oxides shift from 4.96 to $5.49 \mathrm{eV}$ (compare Figure $2 \mathrm{~b}$ and Figure $5 \mathrm{c}$ ). In contrast, the $\mathrm{Mn} 3 \mathrm{~s}$ spectrum of $\mathrm{Mn}_{2} \mathrm{O}_{3}$ remains almost unchanged after 10 minutes of ORR, coherent with thermodynamic expectations.
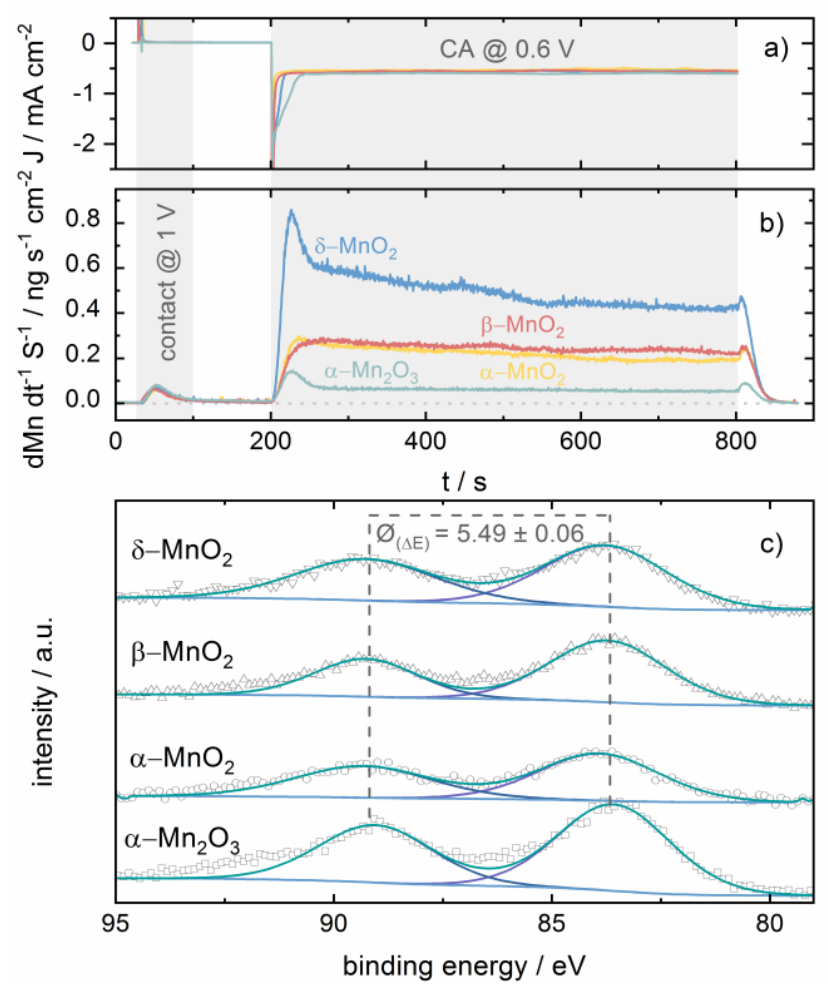
Figure 5. Chronoamperometric (CA) curves recorded on all catalysts over 10 min at $0.6 \mathrm{~V}_{\mathrm{RHE}}$ in $\mathrm{O}_{2}$ purged $0.05 \mathrm{M} \mathrm{NaOH}$ (a) and $\mathrm{Mn}$ dissolution rate vs time (b). XPS $\mathrm{Mn} 3 \mathrm{~s}$ region of the same catalysts after the CA experiment with indicated peak splitting (c).

\subsection{Degradation during the oxygen evolution reaction}

To fully understand the degradation of $\mathrm{MnO}_{x}$ catalysts and to probe their applicability for OER, we also investigate $\mathrm{Mn}$ oxides stability at higher anodic potentials. For this, we use a previously reported method of correlating the dissolved amount of active species with the anodic current passed. ${ }^{19}$ Figure 6 shows the dissolution rate during a LSV from $1 \mathrm{~V}_{\mathrm{RHE}}$ to a potential which corresponds to current density of $1 \mathrm{~mA} \mathrm{~cm}^{-2}$, from which the stability numbers (S-numbers) were calculated. ${ }^{19}$ While all catalysts show a similar onset potential of OER, the extent of dissolution varies between oxides. Most noticeably it is seen in case of $\delta-\mathrm{MnO}_{2}$, which also exhibits much slower OER kinetics. Nevertheless, it produces the highest amount of oxygen per atom dissolved with an S-number of 160 . Other structures $\alpha-\mathrm{Mn}_{2} \mathrm{O}_{3}(90), \alpha-\mathrm{MnO}_{2}(140)$ and $\beta-\mathrm{MnO}_{2}(60)$ are within the same order of magnitude. Considering that state of the art commercial $\mathrm{IrO}_{x}$ catalyst reach S-numbers of $5 \times 10^{5}$ in acidic media, this is a grim outcome even for cheap, earth abundant materials. Seemingly, the OER stability of $\mathrm{Mn}$ might be more promising in the PEM environment, ${ }^{23,}{ }^{36}$ where stability was even improved by the addition of $\mathrm{Mn} / \mathrm{TiO}_{\mathrm{x}}$ surface layers. ${ }^{57}$ This advantage in acid is also due to the $\mathrm{pH}$ dependent character of the $\mathrm{MnO}_{2} / \mathrm{MnO}_{4}{ }^{-}$(aq) couple on the RHE scale allowing higher overpotentials to the $\mathrm{H}_{2} \mathrm{O} / \mathrm{O}_{2}$ couple in acidic electrolytes. ${ }^{13}$ 

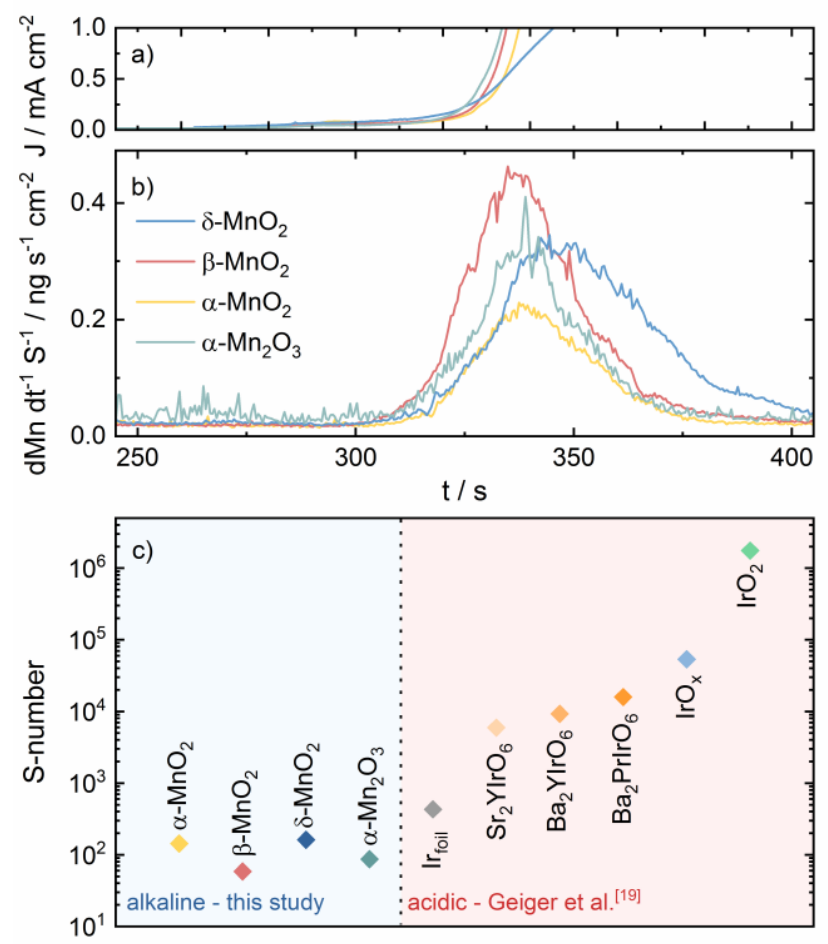

Figure 6. Dissolution of the $\mathrm{MnO}_{\mathrm{x}}$ in the potential range corresponding to oxygen evolution reaction. (a) LSV recorded from $1 \mathrm{~V}$ to a potential corresponding to $1 \mathrm{~mA} \mathrm{~cm}^{-2}$. Scan rate $10 \mathrm{mV} \mathrm{s}^{-1}$. (b) Corresponding Mn dissolution profiles. (c) Comparison of S-numbers for $\mathrm{Mn}$ oxides with literature values for Ir-based oxide in acid.

\section{Discussion}

Generally, electrocatalyst degradation has been shown to be influenced by various factors. The most studied example is carbon supported platinum for which degradation is typically narrowed down to mechanisms like Ostwald ripening, agglomeration and particle detachment, as factors of morphology and synthesis method, as well as support and finally catalyst corrosion as an intrinsic consequence of the materials thermodynamic tendency. ${ }^{56,58-59}$ As this study shows, in the experiments conducted during ORR, an additional cause of corrosion can be the catalytic reaction itself by forming unfavorable side products due to slow kinetics on non-noble metals and in this case $\mathrm{Mn}$ oxides. In the following we differentiate between transient-, ORR-, and OER-dissolution.

As a basis for discussion we first focus on the thermodynamics of $\mathrm{Mn}$ in aqueous solutions without the influence of oxygen and its possible reduction side products during ORR. Therefore, Table 1 summarizes reported thermodynamic potentials ${ }^{13}$ of redox reactions that can play a role in $\mathrm{Mn}$ dissolution during potentiodynamic operation. These transitions are the major reason for transient-dissolution on $\mathrm{MnO}_{\mathrm{x}}$ in an argon purged environment as seen in 
Figure 2a. While the reactions in Table 1 are more complex and plentiful as in a comparable table for state of the art PEM Pt catalysts, intensively investigated over the last years, ${ }^{55}$ we still observe similar behavior of $\mathrm{MnO}_{\mathrm{x}}$. Thus, some parallels can be drawn. In essence, if at a given potential the thermodynamically stable $\mathrm{Mn}$ oxidation state is not the one of the bulk oxide, surface oxides start to change their oxidation state and therefore their coordination by neighboring atoms. During this transition, some of the $\mathrm{Mn}^{\mathrm{n}+}$ cations can be hydrated by the aqueous electrolyte and diffuse through the electrochemical double layer into the bulk solution. These $\mathrm{Mn}$ ions in the bulk electrolyte then represent transient dissolution in the on-line ICP-MS measurement. 
Table 1. Redox transitions of $\mathrm{Mn}$ and $\mathrm{H}_{2} \mathrm{O}$ relevant to the surface processes at $\mathrm{p}$ 12.7.

\begin{tabular}{|c|c|c|}
\hline$\#$ & Redox Transitions $^{a}$ & $E_{0}$ (V vs. SHE) \\
\hline & Manganese & \\
\hline $1_{(s / s)}$ & $\mathrm{Mn}+2 \mathrm{OH}^{-} \rightleftharpoons \mathrm{Mn}(\mathrm{OH})_{2}+2 \mathrm{e}^{-}$ & $-0.727-0.0591 \times \mathrm{pH}$ \\
\hline $2(s / s)$ & $3 \mathrm{Mn}(\mathrm{OH})_{2}+2 \mathrm{OH}^{-} \rightleftharpoons \mathrm{Mn}_{3} \mathrm{O}_{4}+4 \mathrm{H}_{2} \mathrm{O}+2 \mathrm{e}^{-}$ & $0.462-0.0591 \times \mathrm{pH}$ \\
\hline $3_{(s / s)}$ & $2 \mathrm{Mn}_{3} \mathrm{O}_{4}+2 \mathrm{OH}^{-} \rightleftharpoons 3 \mathrm{Mn}_{2} \mathrm{O}_{3}+\mathrm{H}_{2} \mathrm{O}+2 \mathrm{e}^{-}$ & $0.689-0.0591 \times \mathrm{pH}$ \\
\hline $4_{(s / s)}$ & $\mathrm{Mn}_{2} \mathrm{O}_{3}+2 \mathrm{OH}^{-} \rightleftharpoons 2 \mathrm{MnO}_{2}+\mathrm{H}_{2} \mathrm{O}+2 \mathrm{e}^{-}$ & $1.014-0.0591 \times \mathrm{pH}$ \\
\hline \multirow[t]{2}{*}{$5_{(s / a q)}$} & $\mathrm{MnO}_{2}+4 \mathrm{OH}^{-} \rightleftharpoons \mathrm{MnO}_{4}^{-}+2 \mathrm{H}_{2} \mathrm{O}+3 \mathrm{e}^{-}$ & $1.692-0.0788 \times \mathrm{pH}+0.0197 \log \left(\mathrm{MnO}_{4}^{-}\right)$ \\
\hline & Hydrogen Peroxide & \\
\hline $6_{(a q / a q)}$ & $3 \mathrm{OH}^{-} \rightleftharpoons \mathrm{HO}_{2}^{-}+\mathrm{H}_{2} \mathrm{O}+2 \mathrm{e}^{-}$ & $2.119-0.0886 \times \mathrm{pH}+0.0295 \log \left(\mathrm{HO}_{2}^{-}\right)$ \\
\hline $7_{(\mathrm{aq} / \mathrm{g})}$ & $\mathrm{OH}^{-}+\mathrm{HO}_{2}^{-} \rightleftharpoons \mathrm{O}_{2}+\mathrm{H}_{2} \mathrm{O}+2 \mathrm{e}^{-}$ & $0.338-0.0295 \times \mathrm{pH}+0.0295 \log \left(\mathrm{pO}_{2} / \mathrm{HO}_{2}{ }^{-}\right)$ \\
\hline $8_{(a q / g)}$ & $2 \mathrm{HO}_{2}^{-} \rightleftharpoons \mathrm{O}_{2}+2 \mathrm{OH}^{-}$ & \\
\hline
\end{tabular}

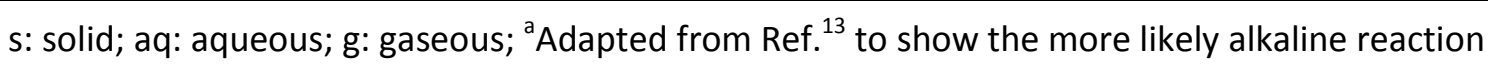

Obviously however, Figure $2 \mathrm{a}$ shows a significant increase in dissolution when the electrolyte is oxygen purged. Interestingly, the potential range of increased dissolution coincides with the increased current density during ORR (Figure 2b) as well as with the detection of $\mathrm{HO}_{2}{ }^{-}$in RRDE experiments (Figure 2c). As it is numerously reported that the production of ROS during ORR can be traced back to poor kinetics on PGM-free electrocatalysts, ${ }^{26,34-35}$ degradation of $\mathrm{MnO}_{x}$ electrocatalysts proceeds to a large extent through surface redox processes initiated by ROS. Therefore, we will further refer to this degradation mechanism as ORR-dissolution.

To show that the extent of ORR-dissolution is a function of the ORR, four $\mathrm{MnO}_{\mathrm{x}}$ with various LSV characteristics (Figure S6b) underwent identical ORR stability tests in $\operatorname{Ar}$ and $\mathrm{O}_{2}$ purged conditions. On-line dissolution rates in Figure 3 a demonstrate that the ORR-dissolution is unavoidable on all investigated $\mathrm{MnO}_{\mathrm{x}}$ catalysts. The apparently most stable oxide is the one comprised of $\mathrm{Mn}^{\prime \prime \prime}$, it's reduction according to reaction \#3 leads to dissolution at $0.63 \mathrm{~V}_{\mathrm{RHE}}$ $\left(0.69 \mathrm{~V}_{\mathrm{th}}\right)$ starting at lower potentials than for the other $\mathrm{Mn}^{\mathrm{IV}}$ oxides. All $\mathrm{Mn}^{\mathrm{IV}}$ oxides dissolve transiently at a potential of $0.88 \mathrm{~V}_{\mathrm{RHE}}$ upon their reduction following reaction \#4 $\left(1.01 \mathrm{~V}_{\mathrm{th}}\right)$. As a more representative characteristic of ORR dissolution Figure 4a summarizes the TDA of Mn during the load cycle experiments normalized to the geometric surface area. Here, the extent of $\mathrm{Mn}$ transient-dissolution follows $\alpha-\mathrm{Mn}_{2} \mathrm{O}_{3}<<\alpha-\mathrm{MnO}_{2} \approx \beta-\mathrm{MnO}_{2}<\delta-\mathrm{MnO}_{2}$. However, keeping the results from $X R D, S E M, B E T$ and $\mathrm{N}_{2}$-purged $C V s$ in mind, it is obvious that there are 
important morphological differences between the different oxides. Therefore, we normalize the same data from Figure $4 a$ to the BET surface area in Figure 7.

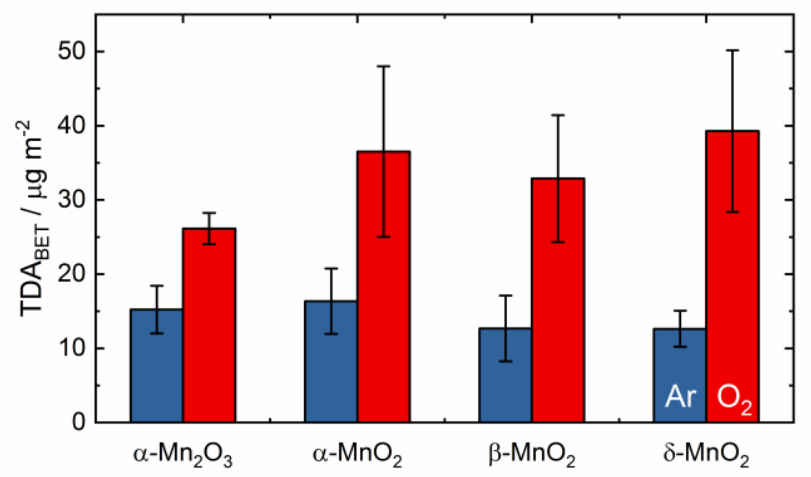

Figure 7. The TDA of Mn on-line dissolution from Figure 4a normalized to the BET surface area, in $\mathrm{Ar}$ (blue) and $\mathrm{O}_{2}$ (red) saturated electrolyte.

Here, no significant impact of crystal structure on the dissolution rate in Ar is observed which relates to the fact that the apparently less stable $\delta-\mathrm{MnO}_{2}$ simply had a much higher surface area from which it can dissolve. More importantly, however, the increased ORR-dissolution is still obvious with a ratio of ORR-dissolution to transient-dissolution of ca. 2 $\left(\alpha-\mathrm{Mn}_{2} \mathrm{O}_{3}, \alpha-\mathrm{MnO}_{2}, \beta-\mathrm{MnO}_{2}\right)$ and even up to 3 for $\delta-\mathrm{MnO}_{2}$. The scaling of $\mathrm{O}_{2}$ to Ar dissolution ratio could suggest, that the leaching of $\mathrm{Mn}^{\mathrm{n}+}$ during transient-dissolution is increased by the presence of $\mathrm{HO}_{2}^{-}$. To strengthen this hypothesis, we further investigated the effect of an intentional addition of $\mathrm{H}_{2} \mathrm{O}_{2}$ to the alkaline electrolyte, in which it undergoes a transition to $\mathrm{HO}_{2}{ }^{-}$which leads to a slight acidification. However, the measured $\mathrm{pH}$ only changed marginally from 12.7 to 12.5 after the highest $\mathrm{H}_{2} \mathrm{O}_{2}$ addition of $10 \mu \mathrm{M}$, ruling out a pH effect. In Figure $3 \mathrm{~b}$ the influence of $\mathrm{HO}_{2}{ }^{-}$concentration on $\mathrm{Mn}$ dissolution is shown for all catalysts during the same potentiodynamic protocol. Here the increase of transient-dissolution with higher $\mathrm{HO}_{2}{ }^{-}$addition, better observed in Figure 4b, supports the above statement that ROS increase degradation of the catalyst during ORR. To explain this, one has to address the thermodynamics of $\mathrm{H}_{2} \mathrm{O}_{2}$ first. $\mathrm{HO}_{2}{ }^{-}$can be considered as redox amphoteric, since it can react as both reducing agent at potentials according to reaction \#7 and oxidizing agent according to reaction \#6. There is only a small window between \#6 and \#7 were it simply disproportionates into $\mathrm{O}_{2}$ and $\mathrm{H}_{2} \mathrm{O}$ (Reaction \#8) without involving other species for electron transfers. In ORR conditions however, where it can be formed according to reaction \#7, it mostly acts as an oxidizing agent towards manganese. This oxidized $\mathrm{Mn}^{\mathrm{n}+}$ species in return is thermodynamically not favored at ORR potentials as discussed earlier (transient-dissolution) and is prone to dissolution. Thereby $\mathrm{HO}_{2}{ }^{-}$ can force stable $\mathrm{MnO}_{\mathrm{x}}$ into an oxidation state where it dissolves. Secondly, ORR-dissolution can also depend on transient radical species formed during the partial reduction of $\mathrm{O}_{2}$, which 
recombine with the manganese oxide to an unstable $\mathrm{Mn}$ surface state. Lastly, the $\mathrm{Mn}^{\text {III/IV }}$ transition can be induced by the ORR catalytic cycle itself as suggested by Ryabova et al. ${ }^{14}$ It is likely that such a catalytic process will cause additional dissolution observed only in oxygen containing electrolyte. To fully grasp the mechanism of surface dissolution during ORR, one would need to identify the charge and coordination environment of the dissolved ion at similarly low detection limits as the ICP-MS, which is currently impossible with state of the art spectroscopic methods. Independent on the operative mechanism however, we demonstrate that ORR and accompanied $\mathrm{HO}_{2}{ }^{-}$production can be harmful for catalyst. Therefore, we urge the PGM-free FC research community to use oxygen in all AST protocols to fully account for all possible degradation mechanisms.

Next to transient- and ORR-dissolution, we detect Mn leaching during start stop cycles with an onset at $1.41 \mathrm{~V}_{\mathrm{RHE}}$ which can be correlated to reaction \#5 and the oxidation of surface $\mathrm{Mn}$ "II oxides following reaction \#4. Presumably, as presented in section 3.2, during ORR cycling all $\mathrm{MnO}_{\mathrm{x}}$ form a reduced oxide surface film. This condition leads us to discussing a third degradation pathway, labelled OER-dissolution which becomes important when we move on to EL or even possible bifunctional applications. Regardless of which oxidation state the original catalyst is in, the surface will always adopt the thermodynamically favored oxidation state. Therefore, when switching the mode of a bifunctional assembly, $\mathrm{MnO}_{\mathrm{x}}$ will always need to cross at least one redox reaction (Table1) leading to transient-dissolution (similar results were recently shown by da Silva et al. for acidic bifunctional ORR/OER Pt//rO catalysts). $^{60}$ Furthermore, ORR- and OER-dissolution need to be accounted for since they occur intrinsically during an applied potential relevant to OER and ORR as an outcome of intermediate species. In case of OER $\mathrm{Mn}$ dissolution can come from the thermodynamically favored soluble $\mathrm{MnO}_{4}{ }^{2-}$ species or from constant surface oxidation state changes during a single catalytic cycle. ${ }^{13,19,}{ }^{37-}$ 38, 61 In case of ORR we contend that the often observed ROS formation during a favored 2- $\mathrm{e}^{-}$ reduction step on PGM-free electrocatalysts significantly increase transient-dissolution. Therefore, we currently cannot confirm long term stability of any investigated crystal structure during ORR, OER let alone bifunctional application. Nevertheless, equilibrium conditions might play an important role in for example metal air batteries, where the dissolved material cannot be diluted by an electrolyte flow, and an equilibrium between dissolution and redeposition can be reached.

\section{Conclusion}

In an effort to understand the stability of Mn-oxides for both the ORR as well as OER, we uncovered an imperative drawback of their highly versatile redox chemistry. First of all, similar to transient dissolution during red/ox transitions in noble metals, we observed the same for $\mathrm{Mn}$ oxides in alkaline environment. Three $\mathrm{Mn}^{\mathrm{IV}}$ and one $\mathrm{Mn}^{\mathrm{III}}$ oxides showed good correlation between dissolution onset potentials and thermodynamic potentials of a transition in oxidation 
state. Especially in a bifunctional device, this can lead to constant degradation, since the catalysts' surface will always rearrange to the thermodynamically favored oxidation state in combination with transient dissolution. The surface transition of four $\mathrm{MnO}_{\mathrm{x}}$ was shown during a CA ORR on-line SFC-ICP-MS experiment, showing constant dissolution while XPS before and after revealed the full transition of the surface to the reduced state. Additionally, to these established degradation mechanisms we observe an increase of up to $300 \%$ TDA $_{M n}$ during ORR. By the means of SFC-ICP-MS and RRDE experiments, we find a good correlation between dissolution rate, ORR currents and $\mathrm{HO}_{2}^{-}$yields suggesting ROS as the main destructive participator. This hypothesis was confirmed by intentional $\mathrm{H}_{2} \mathrm{O}_{2}$ addition revealing a clear dependence of transient dissolution on the $\mathrm{H}_{2} \mathrm{O}_{2}$ concentration. Under OER conditions all investigated $\mathrm{MnO}_{\mathrm{x}}$ revealed comparable stability. Furthermore, with S-Numbers orders of magnitude lower than state of the art PEM electrocatalysts, ${ }^{19} \mathrm{MnO}_{\mathrm{x}}$ do not represent a stable catalyst. This is attributed to their thermodynamic transition to $\mathrm{MnO}_{4}{ }^{-}$(aq) (according to reaction \#5, Table 1). Lastly our results were discussed in regard to bifunctional ORR/OER applications with the pivotal observation, that such potentiodynamic applications lead to constant surface changes and accompanied dissolution. Especially $\mathrm{Mn}$ with such a highly versatile redox chemistry cannot be fully stable in a broad potential window. In short, the three most noticeable degradation mechanisms in such a device would include:

I. Transient dissolution during oxidation state transitions of the surface.

II. Degradation during ORR due to ROS.

III. Dissolution during OER due to constant surface oxidation state changes and a thermodynamic window of corrosion for $\mathrm{Mn}$.

Therefore, we suggest a critical reassessment of bifunctional devices with materials exhibiting transitions in the designated potential operation range. Further we urge researchers to redefine testing procedures, e.g. AST protocols should include $\mathrm{O}_{2}$ so that in operando degradation mechanisms can occur and physical analysis before and after testing can give insights on degradation mechanisms, even without on-line analysis methods.

\section{Associated Content}

XRD peak assignments (Figure S1), XPS Survey spectra of the supported catalysts (Figure S2); SEM analysis if the as prepared $\mathrm{MnO}_{\mathrm{x}}$ (Figure S3); comparison of BET surface area and crystallite size from XRD (Figure S4); additional RRDE analysis of all catalysts (Figure S5 and S6).

\section{Author Information}

Corresponding Authors

*E-mail: F.D.S.: f.speck@fz-juelich.de; F.J.: frederic.jaouen@umontpellier.fr; S.C: s.cherevko@fzjuelich.de 
Notes:

There are no conflicts to declare.

\section{Acknowledgements}

The project CREATE leading to this application has received funding from the European Union's Horizon 2020 research and innovation programme under grant agreement No. 721065.

\section{References}

1. Yoshida, T.; Kojima, K. Toyota Mirai Fuel Cell Vehicle and Progress toward a Future Hydrogen Society. Electrochem. Soc. Interface 2015, 24, 45-49.

2. Cherevko, S.; Keeley, G. P.; Kulyk, N.; Mayrhofer, K. J. J. Pt Sub-Monolayer on Au: System Stability and Insights into Platinum Electrochemical Dissolution. J. Electrochem. Soc. 2016, 163, I122811233.

3. Zhang, T.; Wang, P. Q.; Chen, H. C.; Pei, P. C. A Review of Automotive Proton Exchange Membrane Fuel Cell Degradation under Start-Stop Operating Condition. Appl Energ 2018, 223, 249-262.

4. Shao, M.; Chang, Q.; Dodelet, J. P.; Chenitz, R. Recent Advances in Electrocatalysts for Oxygen Reduction Reaction. Chem. Rev. 2016, 116, 3594-3657.

5. Carmo, M.; Fritz, D. L.; Merge, J.; Stolten, D. A Comprehensive Review on Pem Water Electrolysis. Int J Hydrogen Energ 2013, 38, 4901-4934.

6. Kibsgaard, J.; Chorkendorff, I. Considerations for the Scaling-up of Water Splitting Catalysts. Nat. Energy 2019, 4, 430-433.

7. Greeley, J.; Stephens, I. E.; Bondarenko, A. S.; Johansson, T. P.; Hansen, H. A.; Jaramillo, T. F.; Rossmeisl, J.; Chorkendorff, I.; Norskov, J. K. Alloys of Platinum and Early Transition Metals as Oxygen Reduction Electrocatalysts. Nat. Chem. 2009, 1, 552-556.

8. Speck, F. D.; Dettelbach, K. E.; Sherbo, R. S.; Salvatore, D. A.; Huang, A. X.; Berlinguette, C. P. On the Electrolytic Stability of Iron-Nickel Oxides. Chem 2017, 2, 590-597.

9. Kumar, K.; Gairola, P.; Lions, M.; Ranjbar-Sahraie, N.; Mermoux, M.; Dubau, L.; Zitolo, A.; Jaouen, F.; Maillard, F. Physical and Chemical Considerations for Improving Catalytic Activity and Stability of NonPrecious-Metal Oxygen Reduction Reaction Catalysts. ACS Catal. 2018, 8, 11264-11276.

10. Choi, C. H.; Baldizzone, C.; Grote, J. P.; Schuppert, A. K.; Jaouen, F.; Mayrhofer, K. J. Stability of Fe-N-C Catalysts in Acidic Medium Studied by Operando Spectroscopy. Angew. Chem. Int. Ed. Engl. 2015, 54, 12753-12757.

11. Keeley, G. P.; Cherevko, S.; Mayrhofer, K. J. The Stability Challenge on the Pathway to Low and Ultra-Low Platinum Loading for Oxygen Reduction in Fuel Cells. ChemElectroChem 2016, 3, 51-54.

12. Manberger, A.; Stenqvist, B. Global Metal Flows in the Renewable Energy Transition: Exploring the Effects of Substitutes, Technological Mix and Development. Energy Policy 2018, 119, 226-241.

13. Pourbaix, M., Atlas of Electrochemical Equilibria in Aqueous Solutions. NACE International: 1974.

14. Ryabova, A. S., et al. Rationalizing the Influence of the $\mathrm{Mn}(\mathrm{Iv}) / \mathrm{Mn}$ (lii) Red-Ox Transition on the Electrocatalytic Activity of Manganese Oxides in the Oxygen Reduction Reaction. Electrochim. Acta 2016, 187, 161-172.

15. Wang, L.; Brink, J. J.; Varcoe, J. R. The First Anion-Exchange Membrane Fuel Cell to Exceed $1 \mathrm{~W}$ $\mathrm{Cm}(-2)$ at 70 Degrees $C$ with a Non-Pt-Group (O2) Cathode. Chem. Commun. 2017, 53, 11771-11773.

16. Peng, X.; Omasta, T. J.; Magliocca, E.; Wang, L.; Varcoe, J. R.; Mustain, W. E. Nitrogen-Doped Carbon-Coox Nanohybrids: A Precious Metal Free Cathode That Exceeds $1.0 \mathrm{~W} \mathrm{Cm(-2)} \mathrm{Peak} \mathrm{Power} \mathrm{and}$ $100 \mathrm{H}$ Life in Anion-Exchange Membrane Fuel Cells. Angew. Chem. Int. Ed. Engl. 2019, 58, 1046-1051. 
17. Dekel, D. R. Review of Cell Performance in Anion Exchange Membrane Fuel Cells. J. Power Sources 2018, 375, 158-169.

18. Varcoe, J. R., et al. Anion-Exchange Membranes in Electrochemical Energy Systems. Energ Environ Sci 2014, 7, 3135-3191.

19. Geiger, S., et al. The Stability Number as a Metric for Electrocatalyst Stability Benchmarking. Nat. Catal. 2018, 1, 508-515.

20. Scholz, J.; Risch, M.; Wartner, G.; Luderer, C.; Roddatis, V.; Jooss, C. Tailoring the Oxygen Evolution Activity and Stability Using Defect Chemistry. Catalysts 2017, 7, 10.3390/catal7050139.

21. Santori, P. G.; Speck, F. D.; Li, J.; Zitolo, A.; Jia, Q. Y.; Mukerjee, S.; Cherevko, S.; Jaouen, F. Effect of Pyrolysis Atmosphere and Electrolyte $\mathrm{Ph}$ on the Oxygen Reduction Activity, Stability and Spectroscopic Signature of Fenx Moieties in Fe-N-C Catalysts. J. Electrochem. Soc. 2019, 166, F3311F3320.

22. Suntivich, J.; Perry, E. E.; Gasteiger, H. A.; Shao-Horn, Y. The Influence of the Cation on the Oxygen Reduction and Evolution Activities of Oxide Surfaces in Alkaline Electrolyte. Electrocatalysis 2012, 4, 49-55.

23. Huynh, M.; Shi, C.; Billinge, S. J.; Nocera, D. G. Nature of Activated Manganese Oxide for Oxygen Evolution. J. Am. Chem. Soc. 2015, 137, 14887-14904.

24. Biesinger, M. C.; Payne, B. P.; Grosvenor, A. P.; Lau, L. W. M.; Gerson, A. R.; Smart, R. S. Resolving Surface Chemical States in Xps Analysis of First Row Transition Metals, Oxides and Hydroxides: $\mathrm{Cr}, \mathrm{Mn}$, Fe, Co and Ni. Appl. Surf. Sci. 2011, 257, 2717-2730.

25. Najafpour, M. M., et al. Manganese Compounds as Water-Oxidizing Catalysts: From the Natural Water-Oxidizing Complex to Nanosized Manganese Oxide Structures. Chem. Rev. 2016, 116, 2886-936.

26. Stoerzinger, K. A.; Risch, M.; Han, B. H.; Shao-Horn, Y. Recent Insights into Manganese Oxides in Catalyzing Oxygen Reduction Kinetics. ACS Catal. 2015, 5, 6021-6031.

27. Antoni, H.; Morales, D. M.; Fu, Q.; Chen, Y. T.; Masa, J.; Schuhmann, W.; Muhler, M. Oxidative Deposition of Manganese Oxide Nanosheets on Nitrogen-Functionalized Carbon Nanotubes Applied in the Alkaline Oxygen Evolution Reaction. ACS Omega 2018, 3, 11216-11226.

28. Risch, M.; Stoerzinger, K. A.; Han, B. H.; Regier, T. Z.; Peak, D.; Sayed, S. Y.; Wei, C.; Xu, Z. C.; Shao-Horn, Y. Redox Processes of Manganese Oxide in Catalyzing Oxygen Evolution and Reduction: An in Situ Soft X-Ray Absorption Spectroscopy Study. J. Phys. Chem. C 2017, 121, 17682-17692.

29. Cheng, F.; Chen, J. Metal-Air Batteries: From Oxygen Reduction Electrochemistry to Cathode Catalysts. Chem. Soc. Rev. 2012, 41, 2172-2192.

30. Calegaro, M. L.; Lima, F. H. B.; Ticianelli, E. A. Oxygen Reduction Reaction on Nanosized Manganese Oxide Particles Dispersed on Carbon in Alkaline Solutions. J. Power Sources 2006, 158, 735739.

31. Gorlin, Y.; Lassalle-Kaiser, B.; Benck, J. D.; Gul, S.; Webb, S. M.; Yachandra, V. K.; Yano, J.; Jaramillo, T. F. In Situ X-Ray Absorption Spectroscopy Investigation of a Bifunctional Manganese Oxide Catalyst with High Activity for Electrochemical Water Oxidation and Oxygen Reduction. J. Am. Chem. Soc. 2013, 135, 8525-8534.

32. Gorlin, Y.; Jaramillo, T. F. A Bifunctional Nonprecious Metal Catalyst for Oxygen Reduction and Water Oxidation. J. Am. Chem. Soc. 2010, 132, 13612-13614.

33. Bonnefont, A.; Ryabova, A. S.; Schott, T.; Kéranguéven, G.; Istomin, S. Y.; Antipov, E. V.; Savinova, E. R. Challenges in the Understanding Oxygen Reduction Electrocatalysis on Transition Metal Oxides. Curr. Opin. Electrochem. 2019, 14, 23-31.

34. Ryabova, A. S., et al. Study of Hydrogen Peroxide Reactions on Manganese Oxides as a Tool to Decode the Oxygen Reduction Reaction Mechanism. ChemElectroChem 2016, 3, 1667-1677. 
35. Roche, I.; Chainet, E.; Vondrak, J.; Chatenet, M. Durability of Carbon-Supported Manganese Oxide Nanoparticles for the Oxygen Reduction Reaction (Orr) in Alkaline Medium. J. Appl. Electrochem. 2008, 38, 1195-1201.

36. Li, A.; Ooka, H.; Bonnet, N.; Hayashi, T.; Sun, Y.; Jiang, Q.; Li, C.; Han, H.; Nakamura, R. Stable Potential Windows for Long-Term Electrocatalysis by Manganese Oxides under Acidic Conditions. Angew. Chem. Int. Ed. Engl. 2019, 58, 5054-5058.

37. Rabe, M.; Toparli, C.; Chen, Y. H.; Kasian, O.; Mayrhofer, K. J. J.; Erbe, A. Alkaline Manganese Electrochemistry Studied by in Situ and Operando Spectroscopic Methods - Metal Dissolution, Oxide Formation and Oxygen Evolution. Phys. Chem. Chem. Phys. 2019, 21, 10457-10469.

38. Scholz, J.; Risch, M.; Stoerzinger, K. A.; Wartner, G.; Shao-Horn, Y.; Jooss, C. Rotating Ring-Disk Electrode Study of Oxygen Evolution at a Perovskite Surface: Correlating Activity to Manganese Concentration. J. Phys. Chem. C 2016, 120, 27746-27756.

39. Ching, S.; Roark, J. L.; Duan, N.; Suib, S. L. Sol-Gel Route to the Tunneled Manganese Oxide Cryptomelane. Chem. Mater. 1997, 9, 750-754.

40. Quan, W.; Jiang, C. H.; Wang, S. T.; Li, Y. S.; Zhang, Z. T.; Tang, Z. L.; Favier, F. New Nanocomposite Material as Supercapacitor Electrode Prepared Via Restacking of Ni-Mn Ldh and Mno2 Nanosheets. Electrochim. Acta 2017, 247, 1072-1079.

41. Ghodbane, O.; Pascal, J. L.; Favier, F. Microstructural Effects on Charge-Storage Properties in Mno2-Based Electrochemical Supercapacitors. ACS Appl. Mater. Interfaces 2009, 1, 1130-1139.

42. Cao, X.; Wang, N.; Wang, L.; Mo, C. P.; Xu, Y. J.; Cai, X. L.; Lin, G. A Novel Non-Enzymatic Hydrogen Peroxide Biosensor Based on Ultralong Manganite Mnooh Nanowires. Sensor Actuat B-Chem 2010, 147, 730-734.

43. Klemm, S. O.; Schauer, J. C.; Schuhmacher, B.; Hassel, A. W. A Microelectrochemical Scanning Flow Cell with Downstream Analytics. Electrochim. Acta 2011, 56, 4315-4321.

44. Kijima, N.; Ikeda, T.; Oikawa, K.; Izumi, F.; Yoshimura, Y. Crystal Structure of an Open-Tunnel Oxide A-Mno2 Analyzed by Rietveld Refinements and Mem-Based Pattern Fitting. J. Solid State Chem. 2004, 177, 1258-1267.

45. Bolzan, A. A.; Fong, C.; Kennedy, B. J.; Howard, C. J. Powder Neutron Diffraction Study of Pyrolusite, B-Mno2. Aust. J. Chem. 1993, 46, 939-944.

46. Holland, K. L.; Walker, J. R. Crystal Structure Modeling of a Highly Disordered Potassium Birnessite. Clays Clay Miner. 1996, 44, 744-748.

47. Geller, S. Structure of A-Mn2o3, (Mn0.983fe0.017)2o3 and (Mn0.37fe0.63)2o3 and Relation to Magnetic Ordering. Acta. Crystallogr., Sect. B: Struct. Sci. 1971, 27, 821-828.

48. Norrestam, R.; Ingri, N.; Östlund, E.; Bloom, G.; Hagen, G. Alpha-Manganese(lii) Oxide --- a CType Sesquioxide of Orthorhombic Symmetry. Acta. Chem. Scand. 1967, 21, 2871-2884.

49. Post, J. E.; Veblen, D. R. Crystal-Structure Determinations of Synthetic Sodium, Magnesium, and Potassium Birnessite Using Tem and the Rietveld Method. Am. Mineral. 1990, 75, 477-489.

50. Oku, M.; Hirokawa, K.; Ikeda, S. X-Ray Photoelectron Spectroscopy of Manganese-Oxygen Systems. J. Electron. Spectrosc. Relat. Phenom. 1975, 7, 465-473.

51. Gelius, U.; Hedén, P. F.; Hedman, J.; Lindberg, B. J.; Manne, R.; Nordberg, R.; Nordling, C.; Siegbahn, K. Molecular Spectroscopy by Means of Esca lii.Carbon Compounds. Phys. Scr. 1970, 2, 70-80.

52. Schalenbach, M.; Kasian, O.; Ledendecker, M.; Speck, F. D.; Mingers, A. M.; Mayrhofer, K. J. J.; Cherevko, S. The Electrochemical Dissolution of Noble Metals in Alkaline Media. Electrocatalysis 2017, 9, 153-161.

53. Cherevko, S.; Zeradjanin, A. R.; Topalov, A. A.; Kulyk, N.; Katsounaros, I.; Mayrhofer, K. J. J. Dissolution of Noble Metals During Oxygen Evolution in Acidic Media. ChemCatChem 2014, 6, 22192223. 
54. Pizzutilo, E.; Geiger, S.; Grote, J. P.; Mingers, A.; Mayrhofer, K. J. J.; Arenz, M.; Cherevko, S. On the Need of Improved Accelerated Degradation Protocols (Adps): Examination of Platinum Dissolution and Carbon Corrosion in Half-Cell Tests. J. Electrochem. Soc. 2016, 163, F1510-F1514.

55. Kasian, O.; Geiger, S.; Mayrhofer, K. J. J.; Cherevko, S. Electrochemical on-Line Icp-Ms in Electrocatalysis Research. Chem. Rec. 2018, 1-14.

56. Cherevko, S.; Kulyk, N.; Mayrhofer, K. J. J. Durability of Platinum-Based Fuel Cell Electrocatalysts: Dissolution of Bulk and Nanoscale Platinum. Nano Energy 2016, 29, 275-298.

57. Frydendal, R.; Paoli, E. A.; Chorkendorff, I.; Rossmeisl, J.; Stephens, I. E. L. Toward an Active and Stable Catalyst for Oxygen Evolution in Acidic Media: Ti-Stabilized Mno2. Adv. Energy Mater. 2015, 5, 1500991.

58. Katsounaros, I.; Cherevko, S.; Zeradjanin, A. R.; Mayrhofer, K. J. Oxygen Electrochemistry as a Cornerstone for Sustainable Energy Conversion. Angew. Chem. Int. Ed. Engl. 2014, 53, 102-121.

59. Meier, J. C., et al. Design Criteria for Stable Pt/C Fuel Cell Catalysts. Beilstein J. Nanotechnol. 2014, 5, 44-67.

60. da Silva, G. C.; Mayrhofer, K. J. J.; Ticianelli, E. A.; Cherevko, S. The Degradation of Pt/Irox Oxygen Bifunctional Catalysts. Electrochim. Acta 2019, 308, 400-409.

61. Man, I. C., et al. Universality in Oxygen Evolution Electrocatalysis on Oxide Surfaces. ChemCatChem 2011, 3, 1159-1165. 
TOC Graphic

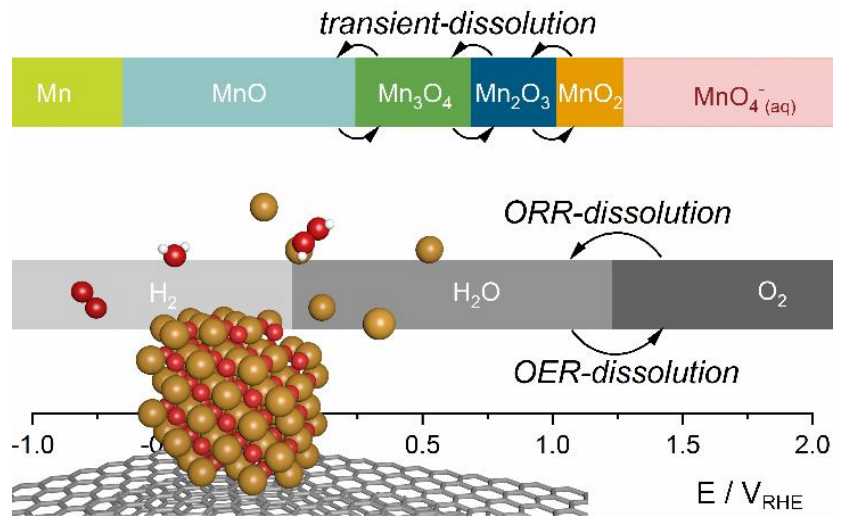

